\title{
СРАВНИТЕЛЬНАЯ ОЦЕНКА ЦИТОТОКСИЧЕСКОЙ АКТИВНОСТИ И СЕЛЕКТИВНОСТИ СЕРИИ ГАЛОГЕНПРОИЗВОДНЫХ АЛКАЛОИДА ФАСКАПЛИЗИНА
}

\author{
П.А. Смирнова, С.А. Стадник, С.А. Дышловой, М.Е. Жидков
}

Школа Естественных Наук, Дальневосточный Федеральный Университет (ДВФУ), 690922, Россия, г. Владивосток, о. Русский, п. Аякс, 10.

DOI: 10.19163/MedChemRussia2021-2021-310

E-mail: smirnova_pa@dvfu.ru

Алкалоид морского происхождения фаскаплизин (1) обладает широким спектром биологической активности [1-3] и является одним из перспективных соединений-лидеров для разработки новых лекарственных препаратов для лечения широкого спектра заболеваний. Однако высокая токсичность фаскаплизина ограничивает его применение в качестве лекарственного средства. Таким образом, актуальной задачей является поиск и исследование производных данного алкалоида, обладающих сходной или большей активностью, но меньшей токсичностью, а также разработка путей их синтеза.

Была проведена сравнительная оценка эффективности и селективности цитотоксического действия фаскаплизина и серии его галогензамещенных производных 2-9 на культурах опухолевых (рак простаты) и неопухолевых клеток (таблица).<smiles>[R]c1cc2c(cc1[R])-[n+]1ccc3c([nH]c4c([R6])c([R5])c([R4])c([R3])c43)c1C2=O</smiles>

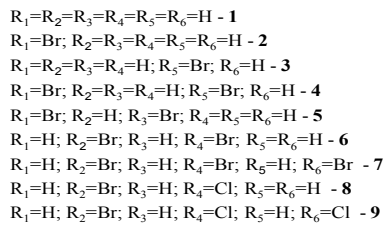

Таблица

\begin{tabular}{|c|c|c|c|c|c|c|c|c|c|c|}
\hline & \multirow{2}{*}{$\begin{array}{c}\text { Куль- } \\
\text { тура }\end{array}$} & \multicolumn{9}{|c|}{ IC50, мкмоль/л } \\
\hline & & 1 & 2 & 3 & 4 & 5 & 6 & 7 & 8 & 9 \\
\hline \multirow{4}{*}{$\begin{array}{l}\text { Опухолевые } \\
\text { клетки }\end{array}$} & PC-3 & 0,77 & 10,03 & 17,82 & 7,28 & 1,39 & 1,83 & 5,94 & 13,24 & 5,29 \\
\hline & 22Rv1 & 0,24 & 0,42 & 0,50 & 0,69 & 0,21 & 0,49 & 3,98 & 2,89 & 4,15 \\
\hline & DU145 & 0,80 & 1,51 & 1,27 & 1,50 & 0,33 & 0,91 & 13,20 & 2,08 & 6,91 \\
\hline & LNCaP & 0,41 & 1,25 & 0,46 & 0,59 & 0,36 & 1,13 & 7,63 & 2,70 & 6,51 \\
\hline \multirow{3}{*}{$\begin{array}{l}\text { Неопухоле- } \\
\text { вые клетки }\end{array}$} & MRC-9 & 0,89 & 2,30 & 20,27 & 50,00 & 2,07 & 5,00 & 30 & 36,3 & 50 \\
\hline & PNT2 & 0,46 & 0,73 & 0,30 & 3,49 & 0,37 & 0,62 & 4,38 & 3,33 & 2,75 \\
\hline & HEK293 & 0,46 & 1,01 & 0,65 & 0,54 & 0,58 & 0,25 & 2,25 & 0,75 & 2,61 \\
\hline
\end{tabular}

Показано, что среди изученных соединений алкалоид 3,10-дибромфаскаплизин (4) обладает наилучшими показателями селективности цитотоксического действия.

\section{Литература}

[1] R. Soni, L. Muller, P. Furet, J. Schoepfer, C. Stephan, S. Zunstein-Mecker, H. Fretz, B. Chaudhuri // Biochem. Biophys. Res. Commun.- 2000.- № 275.- P. 877-884.

[2] S. Manda, S. Sharma, A. Wani, P. Joshi, V. Kumar, S. K. Guru, S. S. Bharate, S. Bhushan, R. A. Vishwakarma, A. Kumar, S. B. Bharate// European Journal of Medicinal Chemistry.2016.-№107.- P. 1-11.

[3] T. A. Johnson, L. Milan-Lobo, T. C Lorig-Roach, P. Crews, J. L. Whistler // ACS Chemical Neuroscience. - 2016.- V. 8, № 3.-P. 473-485. 